\title{
The Pyramid Chin Augmentation: A New Technique
}

\author{
Valerio Ramieri, MD, PhD, ${ }^{*}$ Francesco Maffia, $M S{ }^{\dagger}$ Valentino Vellone, $M D,^{\dagger}$ \\ Sara Marianetti, DDS, ${ }^{\ddagger}$ and Tito M. Marianetti, MD*
}

Abstract: The surgical approach to chin for esthetical purpose can be isolated or in a combination with other treatments like maxillomandibular surgery. Both possibilities include sliding genioplasty or implants of autologous or alloplastic materials. In this article, the authors present their new technique, the Pyramid Chin Augmentation.

In January 2020, a 40-year-old male patient came to authors' observation asking for a great augmentation in the sagittal dimension of the chin, a better pronunciation of mandibular angles and of his cheekbones. The surgical treatment consisted in three different procedures at the same time: a chin wing osteotomy, a Pyramid Chin Augmentation and zygomatic PEEK custom-made malar implants. The pyramid was created on the body of the chin wing with a cortical bone graft from the oblique line of the ascending ramus of the mandible. The harvested bone was cut into strips of rectangular shape gradually shorter to be superimposed on the wing forming a pyramid. A fixation with 2 screws was performed and then was necessary to smoothen the edges of the bone layers.

The result immediately after the end of the surgery was in line with the set goals. The mandibular angles were more prominent, the chin was more sagittal pronounced, and there was no evidence of depression in the symphysial region.

The Pyramid Chin Augmentation Technique can be a valid tool in chin augmentation surgery and can also represent an effective procedure in the finishing touch of other facial surgery techniques.

Key Words: Chin surgery, genioplasty, orthognatic surgery

(J Craniofac Surg 2020;00: 00-00)

$\int^{f}$ all the characterizing elements of the face, the chin is certainly one of the most decisive ones. The treatment of chin morphological abnormalities is a very exciting challenge to solve a cause of plenty of available techniques. Depending on cases and patients, there are 2 major options: minimally invasive treatment or surgical treatment. In the first category, injection of dermal fillers and autologous fat transfer are described. ${ }^{1}$ The surgical approach to chin can be isolated or in a combination with other treatments like maxillomandibular surgery. The chin surgery includes sliding genioplasty or implants of autologous or alloplastic

From the *Maxillo-Facial Surgeon, Ortognatica Roma; $\dagger$ Dipartimento di Scienze Odontostomatologiche e Maxillo-Facciali, "La Sapienza" Università di Roma, Viale del Policlinico; and $\ddagger$ Ortognatica Roma, Via

Nomentana, Roma, Italy.

Received May 11, 2020.

Accepted for publication August 14, 2020.

Address correspondence and reprint requests to Valentino Vellone, MD,

Via Pietro da Cortona, 8, Roma 00196, Italy;

AQ3 E-mail: valentino.vellone@gmail.com

The authors report no conflicts of interest.

Copyright $\odot 2020$ by Mutaz B. Habal, MD

ISSN: $1049-2275$

DOI: $10.1097 /$ SCS.0000000000007074 materials like PEEK, MEDPOR, or silicon. In this article, the authors present their new technique in the field of chin surgery for esthetical purposes, the Pyramid Chin Augmentation.

\section{PATIENT AND METHODS}

In January 2020, a 40-year-old male patient came to authors' observation asking for an improvement in the wideness of mandibular angles and a great augmentation in the sagittal dimension of the chin. He was also interested in more pronounced cheekbones. His CBCT soft tissues reconstruction is showed in (Fig. 1A). In February 2020, the patient underwent surgery. The surgical treatment consisted in 3 different procedures at the same time: the first one was a modified chin wing osteotomy ${ }^{2}$ with the removal of a tiny triangle in the middle of the symphysis to allow a posterior widening in the wings; then authors performed the Pyramid Chin Augmentation technique on the body of the chin wing with a cortical bone graft from the oblique line of the right mandibular ascending ramus; the last one was the implantation of zygomatic PEEK custom-made implants by intraoral maxillary incision.

\section{Surgical Technique}

The implantation of the osseous pyramid is performed under general anesthesia. The patient lies in dorsal decubitus e and the intubation is nasotracheal. Intraoral vestibular mucosa is incised with an electric scalpel and then the inferior border is reached by

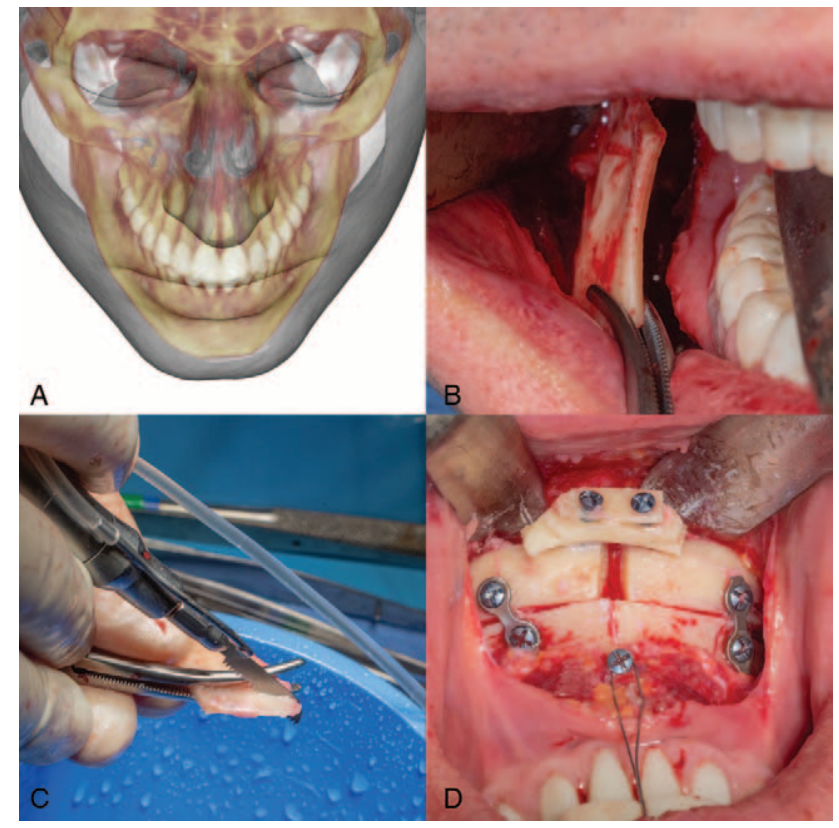

FIGURE 1. (A) Hard and soft tissue reconstruction obtained from the CBCT with DOLPHIN IMAGING. (B) Bone graft harvested from the right ascending ramus of the mandible. (C) Bone strips of rectangular shape preparation with saw. (D) Final result of the Pyramid Chin Augmentation. 


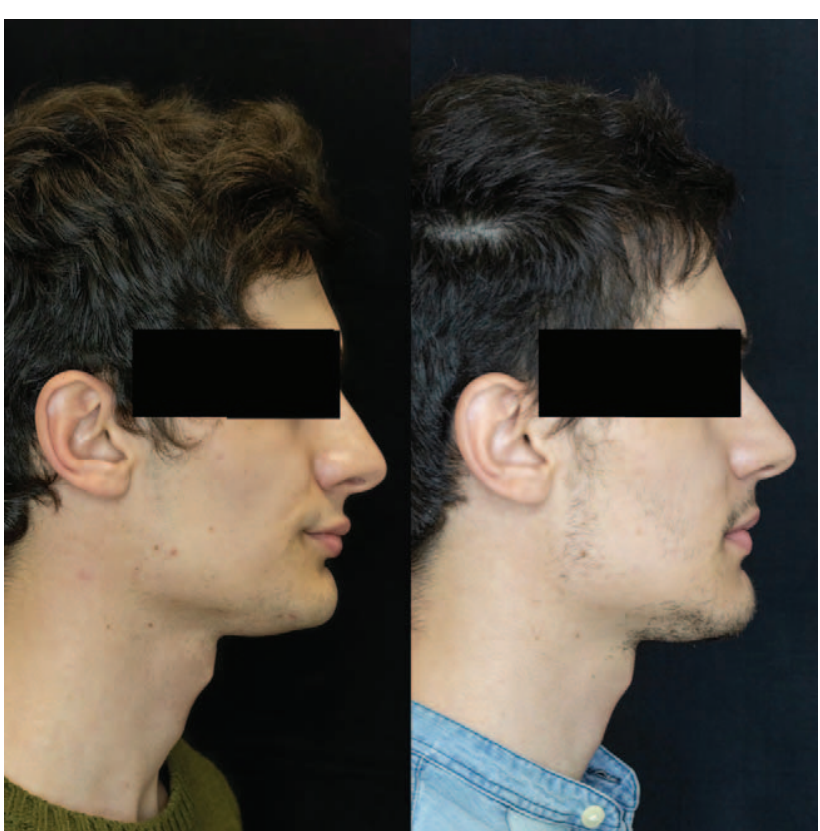

FIGURE 2. Pre- and post-op after 1-year follow-up.

subperiosteal dissection. A further incision is realized as a classic genioplasty: $5 \mathrm{~mm}$ above the buccal sulcus, from canine to canine. ${ }^{3}$ Once the entire anterior face of the mandibular symphysis is exposed, the autologous bone is taken from the ascending ramus of the mandible. Using a piezoelectric device a rectangular lamina of cortical bone is taken from the external face of the ramus, close to the oblique line (Fig. 1B). The harvested bone is cut into strips of rectangular shape gradually shorter, to be superimposed on the wing forming a pyramid (Fig. 1C). The number of bone strips was 3 . The intraoperative result achieved with 3 bone layers was satisfying, so a fixation with 2 screws was performed (Fig. 1D). After fixation, it was necessary to smoothen the edges of the bone layers, both to achieve maximum symmetry and to prevent them from being uncomfortable during palpation. Once the pyramid is fixed and well smoothed, it is very important to cover it strictly with a muscular flap: in this way, the bone resorption is minimized. The incision closure starts with $\geq 2$ single stitches on the muscular plane 4.0 resorbable suture, then the vestibular mucosa is closed with a continuous suture with the same stitch.

\section{RESULTS}

The result immediately after the end of the surgery was in line with the set goals. Soft tissues showed an improvement in the definition of the entire mandible border. The mandibular angles were more prominent, the chin was more sagittal pronounced, and there was no evidence of depression in the para or symphysial region. The postoperative course was free from common short-term complications like bleeding, infection, skin sensory alteration, and temporary teeth sensory disturbance (Fig. 2). ${ }^{4}$

\section{DISCUSSION}

The chin has a crucial role in the face proportion and it also influences the perception of attractiveness and youthfulness. ${ }^{1}$ In addition to its esthetic role, it is a fundamental element in the gender recognition. ${ }^{5}$ The chin morphological abnormalities are evaluable as an excess of an insufficiency in the 3 dimensions of the space: vertical, transversal, and sagittal. ${ }^{6}$

In this case, the authors faced 2 different challenges: the first was the definition of mandibular angles and a vertical increase of these at the same time of width. However, an isolated chin wing could not solve the second issue of a chin depression dimple-like. Performing an advancement associated with a counterclockwise rotation of the wing would have placed the chin-wing in a situation of noncontact posteriorly and anteriorly with high risk of resorption. Graft was the solution for chin sagittal projection without an anterior movement of the chin wing. The realization of a bone pyramid in a combination with a chin wing seemed to be the correct approach to reach the wanted results. The biggest benefit of using this technique was in creating a unique anatomical unit to enhance both mandibular angles and chin. The choice of bone grafting has many advantages: tissue compatibility with consequent minor inflammatory response ${ }^{7}$ and especially the great freedom to shape, add or remove material to it as wanted. Ascending ramus was preferred to symphysis as a donor site to harvest a graft a cause of the less incidence of postoperative complications. ${ }^{4}$ It was the only possibility in this case because of the chin wing osteotomy.

Traditional genioplasty was discarded because it would not have changed the shape in the symphyseal region. Silicon chin implants drawback was the risk of resorption at the interface implant-bone. Porous polyethylene usually presents higher risk of infection and was not adopted. In literature there is no mention of a technique like this, especially as part of a more complex surgery made by $>1$ procedure.

\section{CONCLUSIONS}

The Pyramid Chin Augmentation Technique can be a valid tool in chin augmentation surgery, especially in cases in which particular changes in soft tissue are requested such as a dimple-like deformity. This novelty can represent an effective procedure in the finishing touch of other facial surgery techniques.

\section{REFERENCES}

1. Vanaman Wilson MJ, Jones IT, Butterwick K, et al. Role of nonsurgical chin augmentation in full face rejuvenation: a review and our experience. Dermatol Surg 2018;44:985-993

2. Triaca A, Minoretti R, Saulacic N. Mandibula wing osteotomy for correction of the mandibular plane: a case report. Br J Oral Maxillofac Surg 2010;48:182-184

3. Ferretti C, Reyneke JP. Genioplasty. Atlas Oral Maxillofac Surg Clin North Am 2016;24:79-85

4. Reininger D, Cobo-Vázquez C, Monteserín-Matesanz M, et al. Complications in the use of the mandibular body, ramus and symphysis as donor sites in bone graft surgery. A systematic review. Med Oral Patol Oral y Cir Bucal 2016;21:e241-e249

5. Deschamps-Braly J. Feminization of the chin: genioplasty using osteotomies. Facial Plast Surg Clin North Am 2019;27:243-250

6. Pouzoulet P, Cheynet F, Guyot L, et al. Chin wing: Technical note. $J$ Stomatol Oral Maxillofac Surg 2018;119:315-318

7. Romo T 3rd, Lanson BG. Chin augmentation. Facial Plast Surg Clin North Am 2008;16:69-77 


\section{$\mathrm{SCS}$}

Journal of Craniofacial Surgery

Manuscript No. SCS-20-01023

Dear Author,

During the preparation of your manuscript for typesetting, some queries have arisen. These are listed below. Please check your typeset proof carefully and mark any corrections in the margin as neatly as possible or compile them as a separate list. This form should then be returned with your marked proof/list of corrections to the Production Editor.

\section{QUERIES: to be answered by AUTHOR}

\begin{tabular}{|l|l|}
\hline QUERY NO. & \multicolumn{1}{c|}{ QUERY DETAILS } \\
\hline$<\mathrm{AQ} 1>\quad$ & $\begin{array}{l}\text { Please confirm whether surnames/family } \\
\text { names (red) have been identified } \\
\text { correctly in the author byline. } \\
\text { Affiliations have been set as per style. } \\
\text { Please check for accuracy of } \\
\text { information. }\end{array}$ \\
$<\mathrm{AQ} 3>\quad \begin{array}{l}\text { Please check and confirm the } \\
\text { corresponding author's name and } \\
\text { relevant details for correctness. }\end{array}$ \\
$\begin{array}{l}\text { If you have color in your proof, please } \\
\text { indicate whether you approve the color } \\
\text { charge by returning the color agreement } \\
\text { with your corrections. The color } \\
\text { agreement can be found at http:// } \\
\text { links.lww.com/SCS/A52. The price for } \\
\text { the first color figure is } \$ 400 . \text { The charge } \\
\text { for each additional color figure is } \$ 100 . \\
\text { If you prefer black and white figures, } \\
\text { please indicate so on your proof } \\
\text { corrections. }\end{array}$ \\
\hline
\end{tabular}

